\title{
Dosage Form Not Applicable
}

National Cancer Institute

\section{Source}

National Cancer Institute. Dosage Form Not Applicable. NCI Thesaurus. Code C48624.

An indication that the dosage form is not relevant or appropriate. 